Article history

Received November 24, 2020

Accepted December 29, 2021

\title{
IMPLEMENTASI SENSOR MAGNETIC DOOR SWITCH UNTUK KEAMANAN LACI UANG YANG BERBASIS INTERNET OF THINGS(IOT) STUDI KASUS TOKO SATOYA
}

\author{
Ghanis Albashit Satoya, Danang Haryo Sulaksono \\ Jurusan Teknik Informatika, Falkultas Teknik Elektro dan Teknologi Informasi Institut Teknologi Adhi Tama \\ Surabaya \\ Email : ganisalbasit@gmail.com, danang_h_s@itats.ac.id
}

\begin{abstract}
Theft is a crime which is an act of taking the property of another person illegally. This is contained in Chapter XXII Articles 362-367 of the Criminal Code. An act of theft exists because it is caused by poverty, ignorance, and economic pressure that tend to make people deviate (theft). Therefore, there is a development of a device with a magnetic sensor that will be installed in a store which can help sellers to be able to provide security in their shop. Researchers made an IoT-based tool for a storage security system using a magnetic door switch sensor. This sensor will be useful for shop owners so that this sensor will be installed in a drawer for storing money or valuables of the shop owner. So when someone is not known to open a drawer that has been installed using a magnetic switch, the alarm will automatically sound and give a notification message to the application that has been connected to the device.
\end{abstract}

Keywords: Magnetic Door Switch Sensor, Wemos D1 / R1 Mini, ESP8266, Monitoring, Android Application.

\begin{abstract}
Abstrak
Pencurian adalah salah satu kejahatan yang merupakan suatu perbuatan mengambil barang milik orang lain dengan cara tidak sah. Hal ini termuat dalam Bab XXII Pasal 362-367 KUH Pidana. Sebuah tindakan pencurian ada karena disebabkan faktor kemiskinan, kebodohan, dan desakan ekonomi yang cenderung membuat orang berbuat menyimpang (pencurian). Maka dari itu ada sebuah pengembangan alat dengan sensor magnetic ini yang akan di pasang di sebuah toko yang nantinya bisa membantu penjual untuk bisa memberikan suatu keamanan yang ada di toko mereka. Peneliti membuat sebuah alat yang berbasis IoT untuk sistem keamanan sebuah tempat penyimpanan menggunakan sensor magnetic door swicth. Sensor ini akan berguna bagi pemilik toko sehingga membuat sensor ini akan dipasang di laci untuk penyimpanan uang ataupun barang berharga pemilik toko. Jadi ketika seseorang tidak di kenal membuka laci yang sudah di pasang menggunakan magnetic switch otomatis alarm berbunyi dan memberikan pesan notif ke aplikasi yang sudah di sambungkan ke alat tersebut.
\end{abstract}

Kata Kunci : Sensor Magnetic Door Switch, Wemos D1/R1 Mini, ESP8266, Monitoring, Aplikasi Android. 


\section{PENDAhULUAN}

Pencurian adalah salah satu kejahatan yang merupakan suatu perbuatan mengambil barang milik orang lain dengan cara tidak sah. Hal ini termuat dalam Bab XXII Pasal 362-367 KUH Pidana [1]. Sebuah tindakan pencurian ada karena disebabkan faktor kemiskinan, kebodohan, dan desakan ekonomi yang cenderung membuat orang berbuat menyimpang (pencurian) [2]. Maka dari itu ada sebuah pengembangan alat dengan sensor magnetic ini yang akan di pasang di sebuah toko yang nantinya bisa membantu penjual untuk bisa memberikan suatu keamanan yang ada di toko mereka, dan dengan adanya alat ini akan bisa membantu untuk mencegah adanya pencurian. Peneliti membuat sebuah alat yang berbasis IoT untuk sistem keamanan sebuah tempat penyimpanan menggunakan sensor magnetic door swicth. Sensor ini akan berguna bagi pemilik toko Satoya sehingga membuat sensor ini akan dipasang di laci untuk penyimpanan uang ataupun barang berharga pemilik toko Satoya. Jadi ketika seseorang tidak di kenal membuka laci yang sudah di pasang menggunakan magnetic switch otomatis alarm berbunyi dan memberikan pesan notif ke aplikasi yang sudah di sambungkan ke alat tersebut.

\section{METODOLOGI}

\section{A) Analisis sistem}

Analisis dan perancangan system ini dilakukan untuk melakukan perancangan pada sistem monitoring menggunakan alat Sensor Magnetic Door Switch dengan di sambungkan memakai microcontroller Wemos D1/R1 Mini dalam sistem penulis. Berikut blok diagram proses penelitian yang akan di lakukan sebagai acuan agar dapat berjalan dengan baik, sebagai berikut:

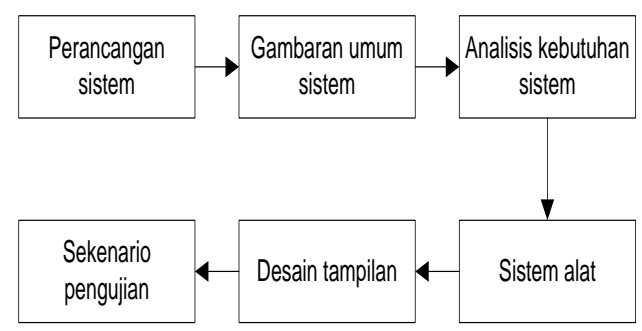

Gambar 1. Blok Diagram Perancangan Sistem
Pada Gambar 1 menjelaskan bahwa tahapan pertama yaitu perancangan sistem untuk gambaran seperti apa kedepannya pembuatan aplikasi monitoring ini agar tidak ada kesalahan dalam pembuatan, tahap kedua yaitu gambaran umum sistem yang bertujuan untuk memberikan suatu alur sistem yang memberikan info seperti apa cara kerja dari sistem monitoring ini, tahap ketiga yaitu analisis kebutuhan sistem bertujuan untuk mempersiapkan kebutuhan-kebutuhan sistem yang di perlukan dalam project ini dari hardware maupun software itu semua harus ada agar bisa memenuhi kebutuhan tersebut, tahap ke empat yaitu merancang suatu sistem yang bertujuan untuk merancang suatu sistem agar alat tersebut berfungsi dengan apa yang diharapkan, maka dari itu dibutuhkan yang namanya sistem alat, tahap ke lima desain tampilan bertujuan untuk merancang desain dari suatu tampilan aplikasi agar terlihat bagus dan rapih agar dengan adanya pembuatan desain bisa memberikan penampilan yang meraik, tahap terakhir yaitu tahap ke enam yaitu skenario pengujian bertujuan apakah sistem tersebut telah berjalan sesuai apa yang di harapkan agar pada saat di pergunakan untuk umum tidak ada kesalahan yang merugikan semua pihak.

\section{B) Gambaran Umum Sistem}

Sistem yang dikembangkan adalah sebuah monitoring sistem keamanan. Pada sistem ini sebuah monitoring sistem keamanan yang akan di terapkan di toko dan di lalukan dengan menggunakan Sensor Magnetic Door Switch yang sudah terhubung ke microcontroller Wemos D1/R1 Mini dan juga menggunakan aplikasi android yang sudah terhubung. Proses penelitian yang akan di rancang pertama adalah membangun sebuah aplikasi dengan fitur sidik jari untuk me-nonaktifkan sensor jika sudah Sensor Magnetic Door Switch yang akan di hubungkan dengan mickrocontroller Wemos D1/R1 Mini serta berfungsi sebagai internet agar bias membuat suatu koneksi. Pada saat sensor tersebut saling berjauhan maka Buzzer yang digunakan untuk alarm akan berbunyi dan langsung mengirimkan data pesan notifikasi dari microcontroller Arduino ke WebService kemudian langsung ke User yang menggunakan aplikasi android yang sudah terhubung dan juga 
fitur sidik jari juga berfungsi sebagai mematikan alarm jika alarm berbunyi.

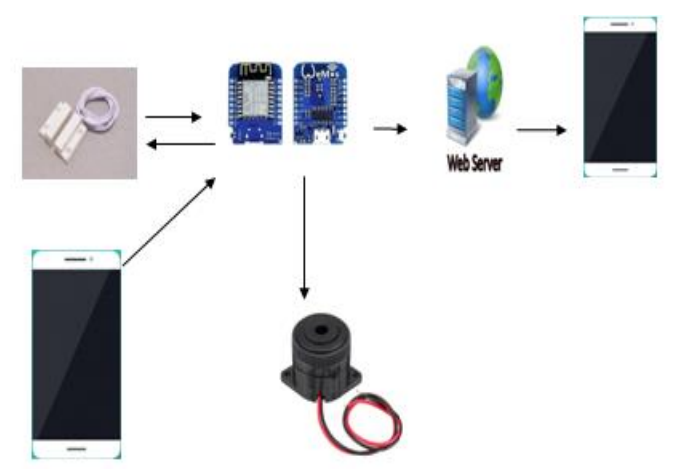

Gambar 2. Gambaran Sistem Secara Umum

\section{C) Sistem Alat}

Yaitu Arduino dan sensor magnetic door switch. Berikut akan di jelasakan alur dari perancangan alat pada gambar 3 Dalam peracangan alat sistem keamanan laci yang ada di toko menggunakan alat sensor tersebut.

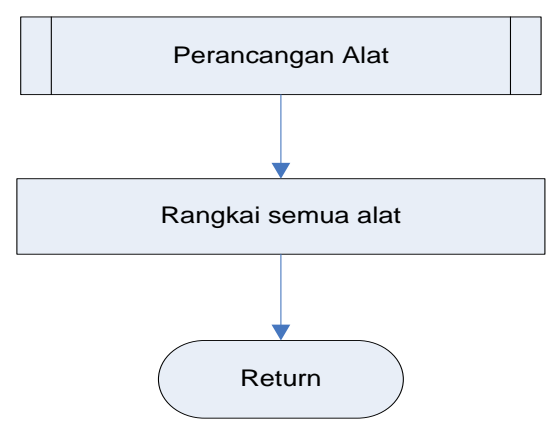

Gambar 3 Alur Rangkai Alat

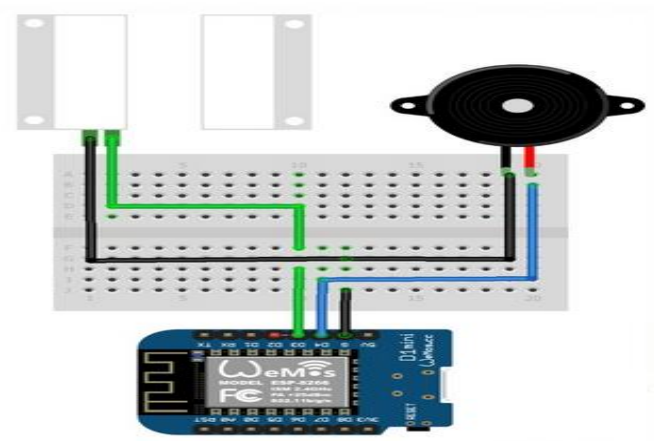

Gambar 4. Rangkaian Alat

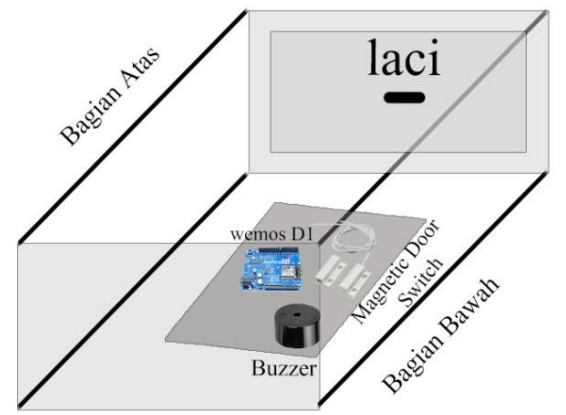

Gambar 5. Rancangan prototype

Penjelasan tentang Gambar 5 perancangan prototype;

Penempatan dari project ini yaitu di bagian bawah laci agar tidak membuat terlihat mencolok maupun mencurigakan bagi orang luar dan juga bagi orang yang tidak di kenal melihat laci tersebut tidak sampai membuat mereka curiga bahwa laci tersebut sudah di pasangkan suatu alat dan sistem monitoring untuk pengawasan yang ada.

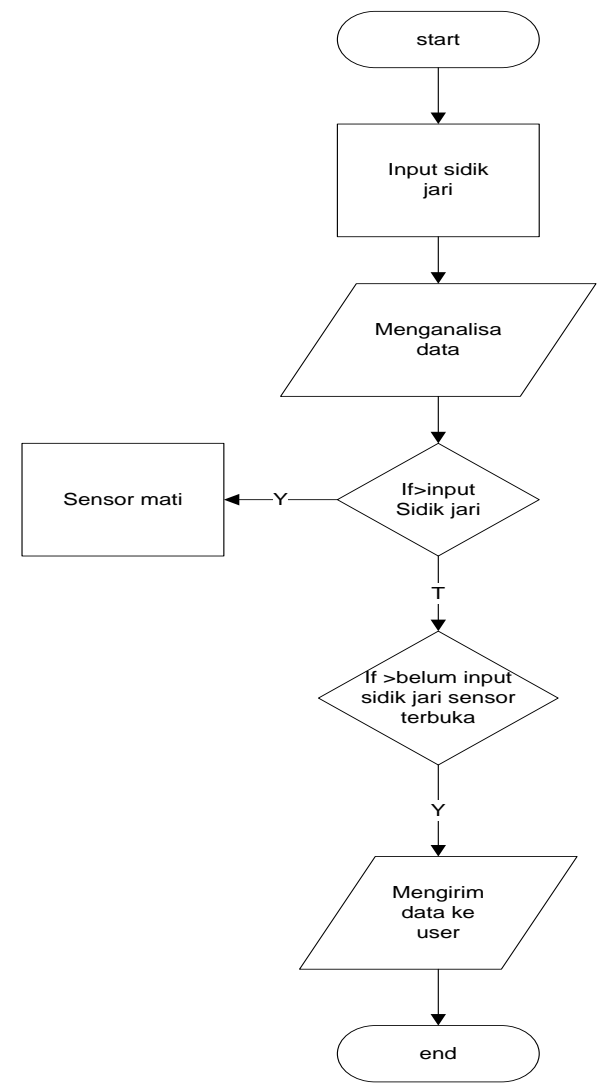

Gambar 6. Flowchart Desain Sistem 


\section{B) Desain Tampilan}

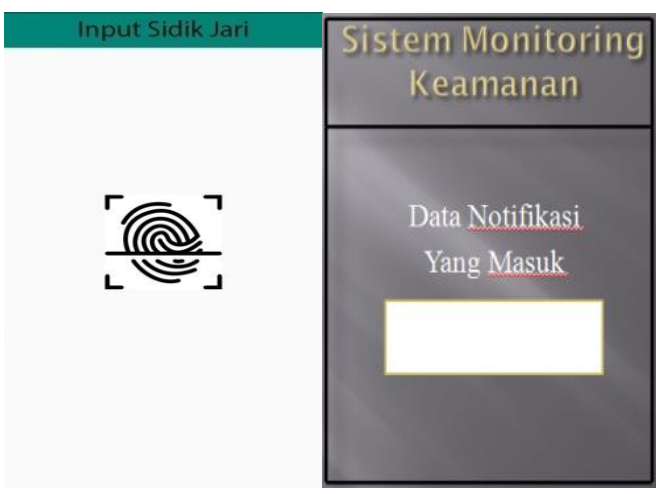

Gambar 7. Desain Monitoring Aplikasi Android

\section{HASIL DAN PEMBAHASAN}

\section{A) Tampilan Bentuk Halaman Utama}

Pada tampilan bentuk utama aplikasi monitoring keamanan laci hanya di tampilkan mengenai pesan notifikasi seperti ada orang membuka laci atau tidak ada orang membuka laci yang terhubung dangn sensor magnetic door switch.

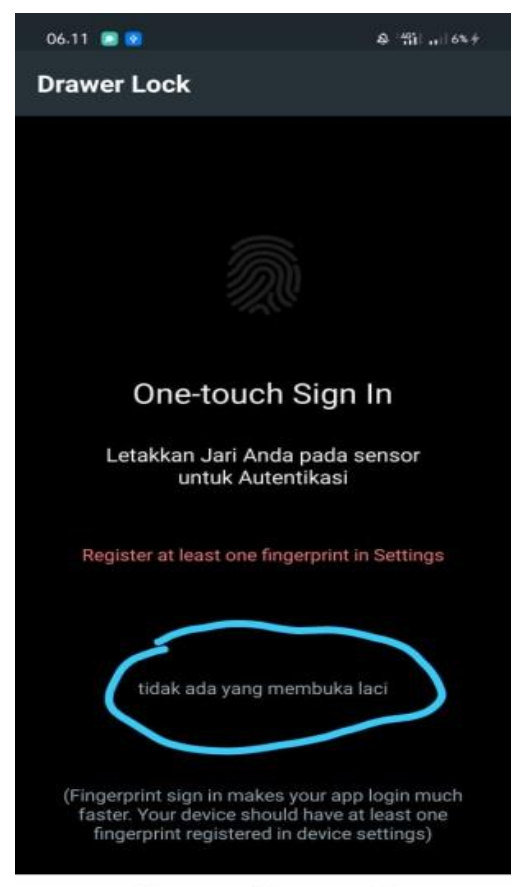

Gambar 8. Tampilan Monitoring Sebelum Ada Orang Buka Laci

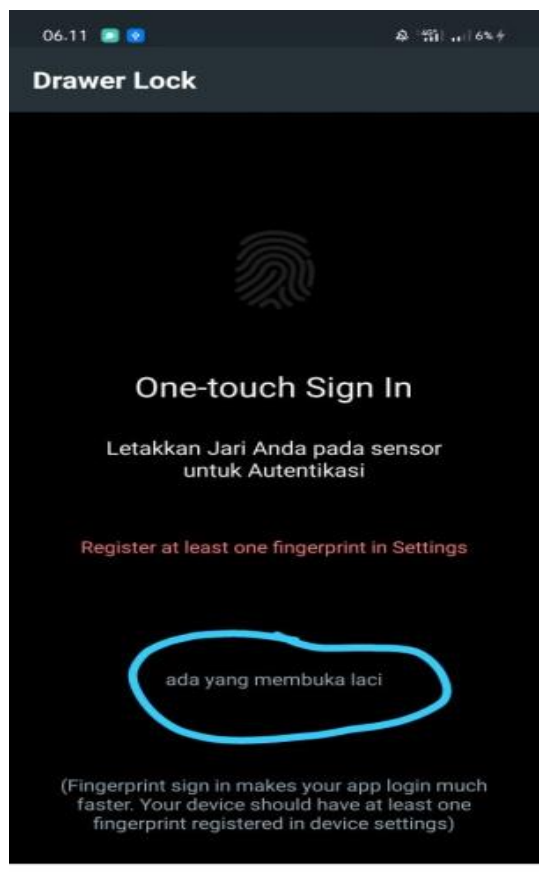

Gambar 9. Tampilan Monitoring sesudah laci dibuka

Pada Gambar 8 menjelaskan tampilan awal aplikasi monitoring keamanan laci yang menunjukkan bahwa ada dua status yaitu tidak ada orang membuka laci dan pada Gambar 9 status kedua yaitu ada orang membuka laci, ketika ada seseorang membuka tanpa finger maka notice nya berubah menjadi ada orang buka laci tapi jika tidak ada maka tetap tertulis tidak ada orang buka laci.

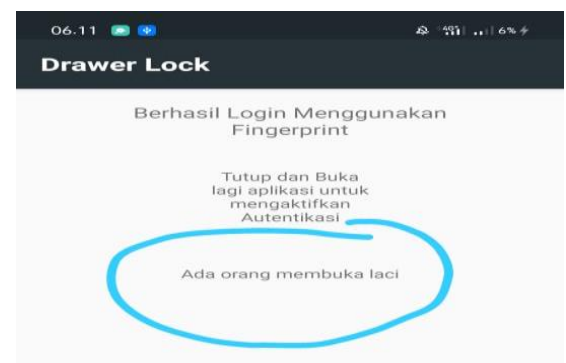

Gambar 10. Tampilan Halaman Kedua 
Pada Gambar 10 menjelaskan bahwa ada dua kemungkinan untuk masuk ke halaman kedua yaitu user sudah login menggunakan finger jika ingin membuka laci serta mematikan alaram dan ketika ada seseorang membuka laci tanpa finger maka user akan mengetahui dan mematikan alarm menggunakan finger lalu masuk ke halaman kedua.

\section{C) Pengujian Sistem}

Pengujian ini sangat penting agar bisa mengetahi bagaimana cara kerja sistem yang telah dibuat seperti adanya kekurangan atau kesalahan yang ada di sistem tersebut. Pengujian ini juga bermaksud untuk bisa mengetahui aplikasi yang di buat sudah layak atau masih perlu di kembangkan lagi. Pengujian ini bertujuan juga agar mendapatkan data yang dibutuhkan, data yang di uji adalah konektivitas ke web hosting firebase dan konektivitas dengan aplikasi android serta alat yang sudah terhubung satu sama lain untuk mengetahui data monitoring berkerja dengan baik atau tidak.

Serta untuk mengetahui bagaimana responsive dari sensor tersebut atau akurasi sensor jika sensor tersebut saling berjauhan satu sama lain maka akan menyalakan buzzer dan mengeirimkan pesan , tapi dengan waktu kurang lebih 1 detik untuk bisa meresponsnya.

Tabel 1. Uji Degradasi Jaringan

\begin{tabular}{|l|l|l|}
\hline $\begin{array}{l}\text { Degradation } \\
\text { Category }\end{array}$ & Packet loss & Jitter \\
\hline perfect & $0.4 \%$ & $2 \mathrm{~ms}$ \\
\hline Good & $0.9 \%$ & $0 \mathrm{~ms}$ \\
\hline medium & $1.3 \%$ & $2 \mathrm{~ms}$ \\
\hline Poor & $2.0 \%$ & $0 \mathrm{~ms}$ \\
\hline
\end{tabular}

Tabel 2. Uji karakter jaringan delay

\begin{tabular}{|l|l|}
\hline \multicolumn{1}{|c|}{$\begin{array}{c}\text { TIPHON QoS } \\
\text { Class }\end{array}$} & \multicolumn{1}{c|}{$\begin{array}{c}\text { Network Delay } \\
\text { Requirements }\end{array}$} \\
\hline 4 best & $<150$ \\
\hline 3 hight & $<178$ \\
\hline 2 medium & $<268$ \\
\hline
\end{tabular}
1 low $<300$

\section{D) Pengujian Akurasi Sensor}

Pengujian ini yang di lakukakan sangat penting karena untuk bisa mengetahui hasil sebuah keakurasian sensor, bagaimana alat ini mulai meresponse dengan jarak tertentu. Untuk itu kita sudah mencoba melakukan pengujian dan mencoba di mulai dari jarak $0.3 \mathrm{~cm}, 0,5,0,8$, dan $1 \mathrm{~cm}$ alat tidak akan merespons atau belum merespons, tapi jika jarak di atas $1 \mathrm{~cm}$ atau lebih dari $1 \mathrm{~cm}$ seperti $1,1,1,3$, dan $1,5 \mathrm{~cm}$ maka, alat tersebut akan aktif atau merespons, seperti hasil table di bawah ini. Dan dengan adanya hasil ini kita bisa mengetahui sensor akan aktif dengan jarak lebih dari $1 \mathrm{~cm}$ atau lebih.

Tabel 3. uji akurasi sensor

\begin{tabular}{|l|l|l|}
\hline No & $\begin{array}{l}\text { Jarak Pengujian } \\
\text { akurasi sensor }\end{array}$ & Meresponse \\
\hline No 1 & $0.3 \mathrm{~cm}$ & Tidak \\
\hline No 2 & $0.5 \mathrm{~cm}$ & Tidak \\
\hline No 3 & $0.8 \mathrm{~cm}$ & Tidak \\
\hline No 4 & $1 \mathrm{~cm}$ & Tidak \\
\hline No 5 & $1.1 \mathrm{~cm}$ & Ya \\
\hline No 6 & $1.3 \mathrm{~cm}$ & Ya \\
\hline No 7 & $1.5 \mathrm{~cm}$ & Ya \\
\hline
\end{tabular}

\section{PENUTUP}

\section{Kesimpulan}

Berdasarkan hasil pengujian sistem yang telah dibuat, maka selanjutnya dapat disimpulkan sebagai berikut :

1. Pengujian sistem yang di hitung menggunakan QoS untuk melakukan pengujian terdiri dari tiga parameter packet loss, jitter dan delay, dari hasil uji packet loss mendapatkan nilai yaitu $0,4 \%$ dengan hasil paling bagus dan hasil paling buruk mendapatkan $2,0 \%$, untuk jitter mendapatkan hasil dengan rata-rata $2 \mathrm{~ms}$ di golongkan dengan hasil yang baik. Kemudian delay mendapatkan hasil $<150$ itu di golongkan hasil paling bagus dan kemudian untuk hasil buruk $<300$. 
2. Pengujian sebuah alat untuk mencoba akurasi seberapa jarak yang di butuhkan untuk mengetahui sensor magnetic door switch akan meresponse jika sensor alat berjauhan yaitu di mulai dari jarak 1,1, 1,3, 1,5 cm dan seterusnya, tapi kalau di mulai dari jarak 0,3 sampai $1 \mathrm{~cm}$ alat tidak akan meresponse.

\section{Saran}

Aplikasi monitoring menggunakan magnetic door switch masih memiliki kekurangan, maka akan dilanjutkan pengembangan lebih lanjut di waktu yang akan datang. Adapun saran terkait skripsi ini adalah sebagai berikut.

1. Disarankan untuk menggunakan jaringan data yang lancar agar tidak menghambat pengujian yang akan dilakukan.

2. Pengembangan selanjutkan di harapkan akan lebih baik dari segi tampilan, aplikasi, fungsi serta jaringan yang harus di perbaiki agar tidak terjadi kendala kedepannya.

\section{REFERENSI}

[1] Moeljatna, Asas-Asas Hukum Pidana. Jakarta: Bina Aksara, 2007.

[2] A. F. Satrya, D. Gustiniati, and R. Fathonah, "ANALISIS KRIMINOLOGIS TENTANG ANAK PELAKU PENCURIAN DENGAN KEKERASAN YANG MENGGUNAKAN SENJATA TAJAM (Studi Kasus Di Wilayah Polres Lampung Timur)," 2017.

[3] H. Hassan, G. Nair, R. Abu Bakar, A. Thaqib, and F. Mokhtar, "Face recognition based on auto-switching magnetic door lock system using microcontroller," ieeexplore.ieee.org, Accessed: Dec. 29, 2021. [Online]. Available:

https://ieeexplore.ieee.org/abstract/docu ment/6339345/.

[4] A. Ramadhan, L. H.-T. com, and undefined 2016, "Rancang bangun sistem keamanan rumah berbasis arduino mega 2560," publikasi.dinus.ac.id, vol. 15, no. 2, pp. 117-124, 2016, Accessed: Dec. 29, 2021. [Online]. Available: http://publikasi.dinus.ac.id/index.php/tec hnoc/article/view/1147.

[5]
K. B. Aji, "IMPLEMENTASI INTERNET OF THINGS MENGGUNAKAN ESP8266 DAN GEEKNESIA," Dr. Diss. Politek. Negeri Padang, 2017. 